\title{
Comentarios
}

\section{Análisis del proyecto de impuestos presentado por el Concejo Municipal de San Salvador}

\section{Antecedentes legales}

La actual Tarifa de Arbitrios Municipales fue decretada el quince de octubre de 1979. La tarifa de impuestos vigentes es sobre los activos y contiene 15 tramos diferentes, lo que dificulta su administración. Además, la estructura impositiva actual es regresiva; es decir, las empresas con activos más altos pagan relativamente menos que las empresas con activos más bajos.

El 21 de diciembre de 1991, la Ley General Tributaria Municipal fue publicada en El Diario Oficial. El artículo 151 de esta ley dice: "Los Municipios deberán modificar la estructura actual de sus sistemas tributarios, sustituyendo aquellos tributos de baja generación de ingresos por otros que generen una mayor recaudación para el debido cumplimiento de los fines del Municipio y con el objeto de simplificar, modernizar y hacer eficientes dichos sistemas. En los casos de creación de nuevos tributos o derogatoria de los ya existentes, deberá darse una justificación de tal medida en los estudios técnicos correspondientes". Además, el artículo 152 dice: "Los Municipios deberán revisar periódicamente sus correspondientes Leyes y Ordenanzas Tributarias, con el propósito de actualizarlos de conformidad a las condiciones de la realidad social económica imperante en el país".

El espíritu de la Ley General Tributaria Municipal es ayudar a fortalecer financieramente a los municipios para que puedan satisfacer eficazmente las necesidades de su localidad. El Concejo Municipal de San Salvador ha justificado legalmente su propuesta en los artículos antes citados.

\section{La propuesta en sintesis}

El Concejo Municipal de San Salvador acordó presentar el proyecto de ley de impuestos del municipio a la Asamblea Legislativa el pasado siete de enero del presente año. Quienes están sujetos a este impuesto son las personas naturales o jurídicas que realizan cualquier actividad económica en el municipio. Sin embargo, quedan exentas de pagarlo los establecimientos ubicados en el interior de los mercados municipales, las ventas ambulantes informales y las ventas de temporada, ya que se encuentran sujetos al pago de tasas municipales. También quedan exentas las instituciones públicas dedicadas a la seguridad social, la Universidad de El Salvador y las instituciones de educación superior de utilidad pública.

El impuesto se determinará sobre el activo imponible, pagando una tasa del 0.36 por ciento anual. Las personas naturales o jurídicas que no estén obligadas a llevar contabilidad formal, pagarán la décima parte del salario mínimo anual o fracción que esté vigente en la ciudad de San Salvador.

\section{Justificación socioeconómica de la propuesta}

El actual Concejo Municipal entró en funciones el pasado 1 de mayo de 1997. En sus primeros meses de labor ha realizado un diagnóstico de las principales necesidades de la ciudad e identificado un conjunto de proyectos considerados prioritarios. Los principales problemas identificados son: el manejo ineficiente de los desechos sólidos, la escasez de mercados, el desorden e inseguridad en 
la ciudad, la saturación en el cementerio, el Rastro Municipal que funciona antihigiénicamente, y el deterioro del Centro Histórico de San Salvador. Además, el Concejo Municipal considera que la actual estructura administrativa de la alcaldía es ineficiente para llevar a cabo las obras y servicios que la ciudad demanda.

Entre los proyectos que se buscan financiar con la mayor recaudación de impuestos se encuentran la rehabilitación del centro (78 millones de colones); el mejoramiento de los mercados (10 millones); los parques (46 millones); la vigilancia (5 millones); el alumbrado público (10 millones); las actividades culturales ( 6 millones); el barrido de calles que comprende equipo, tecnificación y personal (6 millones); la mecanización y modernización administrativa (17.5 millones); el cambio de política laboral acorde a las necesidades (10 millones); la descentralización de los servicios municipales ( 7 millones); la remodelación y ampliación de locales (3.5 millones), y obras sugeridas en las mesas de concertación barrial (245 millones).

El monto total de estos proyectos es de 444 millones de colones. La alcaldía tiene otros proyectos "autofinanciables" como el proyecto integral de desechos sólidos (525 millones de colones). Los representantes de la alcaldía aseguran que ésta funciona con déficit y que actualmente tiene una deuda de 85 millones de colones. Consideran que no es responsable seguirse endeudando y que han realizado un esfuerzo por financiar algunos proyectos sin necesidad de recurrir a impuestos.

Consideraciones sobre la justificación socioeconómica

Prácticamente a ningún ciudadano le agrada pagar impuestos. Sin embargo, son necesarios para financiar los servicios y obras que los gobiernos deben realizar para mejorar el bienestar de la población. Así, antes de proponer un proyecto de impuestos, los gobiernos deben realizar un esfuerzo para concientizar a la población sobre los principales problemas que se enfrentan y lograr una concertación alrededor de las políticas o proyectos por ejecutar. Por tanto, es muy importante mostrarles a los ciudadanos los beneficios esperados de los proyectos y que su dinero será administrado en forma honesta, efectiva y eficiente. A nuestro juicio, la Alcaldía de San Salvador no ha sido efectiva en mostrar los beneficios, debidamente cuantificados, que se esperan de los proyectos de inversión. Más aún, cuando presentan un largo listado de proyectos con sus montos, sin especificar la calendarización de estas obras. Este hecho puede provocar que los ciudadanos piensen que no son realistas con su capacidad de ejecución. En este campo, la alcaldía tiene un gran reto por delante.

\section{Justificación tributaria}

El Concejo Municipal argumenta que la tarifa de impuestos vigente es regresiva, compleja de administrar y anacrónica. La actual tarifa de impuestos contiene 15 tramos diferentes, lo cual dificulta su administración. La propuesta de la alcaldía simplifica la estructura del impuesto al dejar sólo dos categorías: las empresas con activos desde 0.00 hasta 25,000 colones que pagarán la décima parte del salario mínimo anual; y, las empresas con valor de activos de 25,001 en adelante que pagarán el 0.36 por ciento sobre el activo imponible. En este sentido, la propuesta del Concejo cumple con el artículo 151 de la La Ley Tributaria Municipal de simplificar y modernizar el sistema tributario.

La estructura del impuesto vigente es regresiva, es decir, las empresas con valores mayores de activos pagan relativamente menos que las empresas con valores menores de activos. Por ejemplo, una empresa comercial con valor de activos de 25,000 hasta 50,000 paga 1.06 colones por cada 100 colones de activos; mientras que una empresa financiera con activos mayores a 100 millones de colones paga dos centavos por cada 100 colones de activos. Cabe destacar que el 89 por ciento de las empresas comerciales, el 76 por ciento de las empresas financieras y el 82 por ciento de las empresas industriales que actualmente están contribuyendo con este impuesto municipal pagan una tasa mayor a la propuesta de 0.36 por ciento anual sobre el activo imponible. El proyecto incluye una tasa única, con lo cual cada contribuyente pagará proporcionalmente al valor de sus activos.

\section{Evaluación de la justificación tributaria}

Un impuesto sobre los activos

Técnicamente es un impuesto inadecuado al tener como base imponible los activos. El impuesto tiene un efecto cascada. Por ejemplo, si un banco le presta un millón a un constructor, ese dinero representa un activo para el banco y un pasivo 
para el constructor. Se cobraría el impuesto al activo del banco. El constructor realiza un proyecto de tres casas por un millón, que es un activo para él. Se cobraría nuevamente el impuesto sobre el activo generado por el constructor. Lo idóneo sería sustituir este impuesto sobre activos por un impuesto predial. Sin embargo, el impuesto predial requiere de un catastro. La alcaldía no cuenta con un catastro actualizado, planea tenerlo en unos dos o tres años.

Otra posible alternativa es sustituir este impuesto sobre activos por un impuesto sobre el patrimonio, que tomaría en cuenta los pasivos de las empresas. Sin embargo, algunos expertos en el campo de las finanzas públicas argumentan que, por la información requerida por un impuesto sobre el patrimonio, su administración efectiva debería estar en manos del gobierno central. Esto implicaría que los gobiernos locales dependerían de la efectividad del gobierno central en la recaudación del impuesto. Por esta razón, la tendencia es a descartar como opción el patrimonio como base imponible.

En conclusión, se reconoce que la base imponible de los activos es problemática. Sin embargo, el impuesto predial no se puede implementar a corto plazo, y un impuesto sobre el patrimonio scría de difícil administración para la Alcaldía de San Salvador. Por tanto, dado que el impuesto sobre activos es el que históricamente han cobrado los gobiernos locales y que prácticamente no existe alternativa viable a corto plazo, se opta por mantener la base imponible de los activos.

\section{La necesidad de ampliar la base tributaria}

El número de empresas que actualmente pagan impuestos es de aproximadamente 6,511. La alcaldía debe hacer un gran esfuerzo por ampliar su base tributaria, para lo cual el Ministerio de $\mathrm{Ha}$ cienda puede ayudarle brindándole la información pertinente. El mayor impacto del impuesto propuesto recae sobre un número reducido de empresas con altos valores de activos. Los bancos, especialmente los que tienen activos mayores a los 100 millones de colones, experimentarían un incremento considerable. Sin embargo, no todos los bancos sufrirían un gran incremento, ya que algunos tienen agencias importantes en otros municipios no sujetos a este impuesto. Además, la ley establece que

se deben deducir las cantidades aplicadas por los otros municipios donde operen las agencias.

\section{Consideraciones sobre algunos posibles efectos económicos}

Los gremios de la empresa privada, por ejemplo la Cámara de Comercio, han afirmado que el impuesto propuesto por la alcaldía es inflacionario. Analicemos esta posición. En primer lugar, la inflación es un incremento generalizado y continuo en el nivel general de precios. Un impuesto, como tal, puede generar un incremento en el nivel de precios, pero no de manera continua. Es más, ese incremento del nivel de precios dependerá de si la empresa puede trasladar el impuesto al consumidor, lo que a su vez dependerá del tipo de demanda que la empresa tenga. Por ejemplo, si la empresa enfrenta una demanda elástica, el trasladar el impuesto al consumidor, vía incremento en el precio, le puede ocasionar una disminución en la cantidad demandada más que proporcional al incremento del precio $y$, por tanto, sus ingresos totales disminuirían. Generalmente, las empresas no pueden trasladar tolalmente el pago de un impuesto a los consumidores. Por tanto, la afirmación que el impuesto de la alcaldía es inflacionario resulta sin mayor base y una afirmación exagerada. Lo que debe evitarse es crear expectativas inflacionarias o simplemente especulaciones que sí pueden tener efectos inflacionarios.

Uno de los argumentos para afirmar que la propuesta de impuestos de la alcaldía va a generar inflación es que producirá un incremento en las tasas de interés de los bancos. En este aspecto vale la pena hacer algunas consideraciones. Primero, se 
tiene que evaluar si el monto del impuesto es una cantidad significativa de los costos y gastos de funcionamiento de los bancos. Segundo, no todos los bancos se afectarán de igual manera y, por tanto, su posible reacción de trasladar el impuesto vía incremento de la tasa de interés debería ser muy distinta. Si un banco considera incrementar la tasa de interés y piensa que los otros bancos no tomarán la misma medida, este banco tendría que abstenerse de incrementar esta tasa. Tercero, las tasas de interés se determinan, en buena medida, por la interacción de la oferta y la demanda de dinero. En 1998 se espera una entrada de recursos externos provenientes de la venta de activos estatales, una baja inflación (entre el 2 y el 4 por ciento), y una política monetaria menos restrictiva que conducirá a una mayor liquidez en los bancos. Consecuentemente se esperaría una tendencia a que las tasas de interés bajen. En conclusión, resulta exagerado afirmar que el impuesto propuesto por la alcaldía va a producir un incremento en las tasas de interés.

\section{Consideraciones sociopolíticas}

Según la teoría fiscal, éste es un impuesto sobre la riqueza que se justifica, en parte, cuando la sociedad se preocupa por los efectos de la concentración de la riqueza sobre la distribución del poder político. Este tipo de impuesto ha perdido espacio político en El Salvador en la presente década. Por ejemplo, la reforma tributaria de la administración Cristiani eliminó el impuesto sobre el patrimonio, que era un impuesto a la riqueza. Se justificó la eliminación para que fuera sustituido por un impuesto predial a favor de los gobiernos locales, lo cual no se ha realizado todavía. Incluso, la actual estructura tributaria del gobiemo central descansa sobre todo en el IVA, que es un impuesto regresivo. Así, en 1997, la recaudación del IVA significó el 61 por ciento de los ingresos tributarios del gobierno.

Ante esta situación, se deberían abrir espacios para impuestos progresivos que toman una proporción creciente cuando el ingreso aumenta, sin llegar a tasas que afecten considerablemente la inversión. Los impuestos progresivos implican un sacrificio para los que tienen más ingresos y bienes. Juan Pablo II, en su mensaje para la jornada mundial de la paz del presente año, nos recuerda a los cristianos que: "una sociedad auténticamente solidaria se construye gracias al hecho de que quienes tienen bienes, para ayudar a los pobres, no se limiten a dar sólo de lo superfluo".

Algunos sectores de la empresa privada han reaccionado y expresado que este impuesto prácticamente creará un caos en la economía nacional. En el fondo, la viabilidad de esta propuesta de la Alcaldía de San Salvador no depende tanto de sus implicaciones económicas sino de las políticas. El sector privado, representado por las gremiales como ANEP, ABANSA y la Cámara de Comercio, y el partido ARENA están poco dispuestos a financiar los proyectos de la alcaldía. Ya que el éxito de la gestión Silva podría convertirse en la mejor carta de presentación de la capacidad del FMLN para gobernar en las próximas elecciones presidenciales de 1999. Consideramos que es sano racionalizar la discusión para que se pueda entablar una negociación efectiva entre la alcaldía y los sectores que se oponen a esta propuesta, anteponiendo la necesidad de solucionar los graves problemas de nuestra ciudad capital.

Rafael A. Pleitez 